\title{
EGU21-2840
}

https://doi.org/10.5194/egusphere-egu21-2840

EGU General Assembly 2021

(c) Author(s) 2021. This work is distributed under

the Creative Commons Attribution 4.0 License.

\section{Characterization of the Outer Coast Tuff Formation- A way to unravelling the magmatic processes preceding and triggering Deception Island's caldera - forming eruption (Antarctica)}

\author{
Oriol Vilanova ${ }^{1}$, Meritxell Aulinas ${ }^{1}$, Adelina Geyer ${ }^{2}$, Joan Marti ${ }^{2}$, Antonio Álvarez-Valero ${ }^{3}$, Helena \\ Albert ${ }^{1}$, and Guillem Gisbert ${ }^{4}$ \\ ${ }^{1}$ Departament de Mineralogia, Petrologia i Geologia Aplicada, University of Barcelona, Marti Franques s/n, 08028, \\ Barcelona, Spain (oriolvilanovapages@gmail.com; meritxellaulinas@ub.edu; halbert@ub.edu) \\ ${ }^{2}$ Geosciences, GEO3BCN - CSIC, Lluis Sole i Sabaris s/n, 08028, Barcelona, Spain (ageyer@geo3bcn.csic.es; \\ jmarti@geo3bcn.csic.es) \\ ${ }^{3}$ Departamento de Geología, Universidad de Salamanca, 37008 Salamanca, Spain (aav@usal.es) \\ ${ }^{4}$ Instituto de Geociencias, CSIC-UCM, Severo Ochoa 7, 28040 Madrid, Spain (ggisbertp@hotmail.com)
}

Deception Island (South Shetland Islands), discovered in 1820, is one of the most active volcanoes in Antarctica with more than 20 eruptions (including the historic eruptions of 1967, 1969 and 1970) and three documented volcanic unrest events (1992, 1999 and 2014-15) over the past two centuries. Deception Island currently hosts two scientific bases, which operate every year during the Austral summer, and is also one of the most popular tourist destinations in Antarctica. The island is a composite volcano with a centrally located caldera of $8.5 \times 10 \mathrm{~km}$ dated at 3,980 \pm 125 yr. BP. During the caldera-forming event, between 30 and $60 \mathrm{~km}^{3}$ (Dense Rock Equivalent-DRE) of magma, erupted in the form of dense basaltic-andesitic pyroclastic density current deposits. During the last decades, Deception Island has been intensively investigated but some aspects regarding the magmatic processes associated with the formation of its caldera collapse are still under research and debate. For instance, characterizing the magmatic conditions and processes that triggered the huge explosive event is crucial to understand the past (and in turn the future) magmatic and volcanic evolution of the island.

This study is performing an exhaustive petrological and geochemical characterization (mineral and juvenile glass geochemistry) of the Outer Coast Tuff Formation (OCTF), the main syn-caldera depositional unit. The preliminary results confirm the existence of two different magmas coexisting, and interacting, prior to (and during) the caldera-forming event. Mineral analyses also allow shedding further light on the magmatic processes occurring in the magma system before the eruption (e.g. fractional crystallization, magma mixing). The presence of alteration minerals such as palagonite and zeolites indicate different magma-water interaction mechanisms occurred during the syn- and post-eruptive episodes in the island.

This research is part of POLARCSIC and PTIVolcan research initiatives. This research was partially funded by the MINECO grants POSVOLDEC(CTM2016-79617-P)(AEI/FEDER-UE) and VOLGASDEC 
(PGC2018-095693-B-I00)(AEI/FEDER, UE). This research is also supported by the PREDOCS-UB grant. 